\title{
The Impact of a First Year Development Course on Student Success in a Community College: An Empirical Investigation
}

\author{
Edgar Garza ${ }^{1}$, Randall Bowden ${ }^{2, *}$ \\ ${ }^{1}$ Social Sciences, Northwest Vista College, San Antonio, USA \\ ${ }^{2}$ Educational Leadership, Texas A\&M University, Corpus Christi, USA \\ *Corresponding author: Randall.Bowden@tamucc.edu
}

Received February 23, 2014; Revised June 03, 2014; Accepted June 09, 2014

\begin{abstract}
Virtually every institution of higher education in the United States is faced with the issue of student retention and success. The purpose of this study was to examine the effect of a development course toward retention and academic achievement. Specifically, this study focused on the Student Development Course (SDEV) offered at a community college in central Texas, serving 15,000 students. The course focuses on both life skills and study skills, including familiarity with college regulations, communication and study skills, goal setting, priority management, reading for comprehension, note-taking, test-taking, creativity, establishing relationships, and the power of a positive attitude. The research design involved the analysis of existing transcript data that are maintained by the college in its student registration and information data base. Participants included 1557 first-time-in-college students who were required to take a college development course either on campus or online. Data were analyzed with analysis of variance, post hoc analyses, and bivariate correlations. Results were statistically significant. Students who took the developmental course tended to stay in college over a four term time frame. Additionally, it was statistically significant that they had grade point averages at a C or better. Gender was not statistically significant, however ethnicity was. This supports theory suggesting that comprehensive integration programs can lead to student success. Issues for future consideration should include quality of faculty instruction, external forces, academic advising, and student accountability. Finally, researchers could compare students who complete a first-year-in-college program at a community college and continue to four-year institutions.
\end{abstract}

Keywords: community college, first-year-in-college programs, student success

Cite This Article: Edgar Garza, and Randall Bowden, "The Impact of a First Year Development Course on Student Success in a Community College: An Empirical Investigation.” American Journal of Educational Research, vol. 2, no. 6 (2014): 402-419. doi: 10.12691/education-2-6-13.

\section{Introduction}

First-year students, regardless of their background, have trouble adjusting to college life. The largest proportions of students who leave college do so during their first year $[1,2]$. Though, the most critical time for the first-year student is during the first six weeks of the semester. It is especially important for first-year students to establish friendships during the first month of enrollment [3]. Newly formed relationships help to retain first-year college students [4]. However, the inability of first-year students to adapt to the college environment often results in withdrawal from school and/or lower academic performance than expected $[1,2,5]$.

The purpose of this study was to examine the effect of a development course on retention and academic achievement. Specifically, this study focused on the Student Development Course (SDEV) offered at a community college in central Texas, serving 15,000 students. The course, SDEV 0170 employs techniques to assist students in gaining the most from their college education. It focuses on both life skills and study skills and includes such topics as familiarity with college regulations, communication and study skills, goal setting, priority management, reading for comprehension, notetaking, test-taking, creativity, establishing relationships, and the power of a positive attitude. This course is intended to provide the student with skills necessary to assume responsibility for individual learning.

The study also examined instructional methods (faceto-face and online) and two demographic characteristics (gender and ethnicity) as to their relationship to student retention and student achievement. The study used preexisting data from the Community College District student information database.

\subsection{Background}

Virtually every institution of higher education in the United States is faced with the issue of student retention and success [6]. In the early 1980s, as institutions of higher education experienced declining enrollments, 
colleges and universities were forced to investigate new ways of retaining students. Retaining current students, as opposed to recruiting new ones, is generally considered an economically sensible strategy. Yet, attrition rates have remained largely unchanged over the last 30 years [7]. An estimated one third of college students do not complete a degree, and most of them leave within their first year of college [8]. One in four college freshmen do not return to college after leaving [9].

Departing students do not necessarily view leaving as negative. Many of them view leaving as a positive step toward achieving their goals. For example, some students decide to leave college in order to explore another aspect of their personal development through travel, work experience, military experience, or volunteer opportunities. Other students decide to transfer because another institution is better able to serve their needs [10]. However, the institution usually views a student's leaving as a negative event. To help with retention rates many colleges and universities have created transitional programs, such as Freshman Interest Groups and First Year Experience (FYE) programs. Effective programs include elements that integrate students into academic and social communities. This allows students to gain skills and knowledge about the institution. These skills will in turn allow students to be a competent member of the institution [9]. Additionally, retention programs must provide students with the opportunity to obtain the necessary skills and knowledge about the institution at the beginning of an academic year [9].

Although first year experience programs have achieved varying degrees of success, the dropout rate, as reported by the American College Testing Program, has held steady at around 33\% during the past several years [3]. Perhaps this rate would be even higher without the intervention FYE programs provide. First year programs aim to assist students in their academic and social development in addition to their transition to college [11]. They also aim to help persistence and graduation goals [11]. In a national survey of regionally accredited universities and colleges with undergraduate student bodies, $85 \%$ of the institutions reported having some type of first year seminar program [12].

Successful first year experience programs are supported by an outcome assessment process that is strongly connected to the FYE program goals [13]. Assessment results can provide guidance for improvement and program justification. FYE seminars and other programs that service large numbers of first-year students are frequently asked to justify their existence [14]. However, assessment of FYE programs is somewhat limited to student satisfaction surveys and correlation analyses between program participation and one-year enrollment attrition [14]. Often these studies were not properly designed and therefore offered limited information [13], [15]. With budget deficits and increasing accountability demands from state legislatures and accrediting agencies [82], the need to justify the effectiveness of FYE programs will come to the forefront. The importance of assessing FYE programs has been given more attention in recent years. Selecting the best method or tool for assessing a given program requires the institution to ask the questions of why, what, who, when, where, and how [54]. The answers to these six questions will help an institution conduct a meaningful assessment of its first year program.
This study examined whether the SDEV 0170 course has any relationship with retention and academic achievement of first time in college students. The course is intended to provide the student with skills necessary to assume responsibility for individual learning.

\subsection{Research Questions}

Researchers working to investigate the issue of college persistence and achievement speak to various direct or intervening variables that appear to be related to staying in college [16]. Grades earned in a first-year course were better predictors of both college academic achievements and persistence than high school rank and SAT scores [5].

Many programs assist under-prepared and at-risk students. For example, Jones and Becker [79] identified the need for programs that teach decision-making skills, encourage self-advocacy, provide rigorous curriculum advising, and provide services that support students during their first year. These are skills often taught in freshman seminars. Remedial courses such as basic reading, writing, and math skills in their course offerings for at-risk students. There is a need for the identification of programs that have demonstrated success in enhancing student persistence and that can be applied to similar populations at other institutions. Successful first year experience programs are supported by an outcome assessment process that is strongly connected to the FYE program goals [13]. Assessment results can provide guidance for improvement and program justification. First year in college seminars and other programs that service large numbers of first year students are frequently asked to justify their existence [3]. However, assessment of FYE programs is somewhat limited to student satisfaction surveys and correlation analyses of program participation and one-year enrollment attrition [3]. Often these studies were not properly designed and therefore offered limited information [13,79]. This research examines actual course work instead of relying on surveys. The research is guided by the following questions:

RQ1: What is the impact of the SDEV 0170 course on achievement of first time in college students at the college?

RQ2: What is the impact of the SDEV 0170 course on retention of first time in college students at the college?

RQ3: What is the difference between 11 week and online courses of SDEV 0170 course on achievement of first time in college students at the college?

RQ4: What is the difference between 11 week and online courses of SDEV 0170 course on retention of first time in college students at the college?

RQ5: How does achievement differ between students who enrolled in the SDEV 0170 course according to gender?

RQ6: How does retention differ between students who enrolled in the SDEV 0170 course according to gender?

RQ7: How does achievement differ between students who enrolled in the SDEV 0170 course according to ethnicity?

RQ8: How does retention differ between students who enrolled in the SDEV 0170 course according to ethnicity?

\subsection{Theoretical Framework}

Student retention is the area of research concerned with determining the factors that shape student persistence in 
institutions of higher education. The term retention describes an institution's ability to keep a student enrolled and the term persistence describes the student's ability to stay enrolled at the institution. There are two theories that serve as a foundation: (a) Tinto's Student Integration Model [17]; and (b) Astin's Involvement Model [18].

The types of activities in which students engage while attending college are as important to overall success as is the choice of college. The research on college student development shows that the amount of time and energy a student devotes to academically focused activities are the single best predictor of their learning and personal development $[5,10,18]$. Institutions that are better able to engage their students in a variety of value added activities can retain students at a higher rate compared with other colleges and universities where students are less engaged. First year experience programs are among institutional practices known to lead to high levels of student engagement $[10,19,20,21]$.

\subsubsection{Tinto's Theory of Student Departure}

Tinto [17] introduced a theoretical model of student retention that addressed the complex relationship between students and the institutional environment. The theory of student departure is unique in its longitudinal approach. It asserts that a student's decision to remain or depart from an institution results from a series of interactions between that student and members of the college environment. Tinto [17] identified student integration into the academic and social environments of the campus community as the critical piece of the retention puzzle. Integration occurs through experiences between the student and other members of the institution. The level of student integration predicts whether the student will either persist until graduation or voluntarily depart prior to obtaining a degree.

Many researchers have validated the student integration model $[4,22,23,24,25]$. This body of research confirms the connection between student integration and student retention. Student interaction with faculty and the perceived levels of faculty concern for students are acknowledged as the strongest contributors in a student's decision to return or leave the institution [10]. Tinto's conceptual framework of student integration concentrates on variables within an institutional setting that have a longitudinal influence on academic engagement. Poor attendance and the lack of academic success are early signs that a student is disengaging from school. Expanding on the model of disengagement, Bean and Metzner [26] identified other variables to explain why older, nontraditional college students decide not to re-enroll in college. Variables, such as family and work, may force students to leave school by putting too much pressure on their time and resources. Models of engagement offer powerful explanations for academic progress and student persistence to graduation.

The student integration model states that before potential students matriculate in higher education, they will develop attributes that are shaped by their upbringing [17]. At the same time, they develop academic skills, social skills, and other abilities. In turn, these skills and abilities influence the goals and commitments of students' regarding college, the workforce, and their place in society. While a student is enrolled in college, he or she will encounter formal and informal college experiences that influence the level of integration into college. According to Swail, Redd, and Perna [27], the level of integration influences the student's development of goals and commitments, which results in a decision to either reenroll in or leave college. Therefore, the match between student characteristic and institution shapes students' goals and commitment, which in turn influence persistence and retention [27].

\subsubsection{Astin's Theory of Involvement}

Astin's Theory of Involvement [18] related that the more students are involved in both the academic and social aspects of the collegiate experience, the better their academic achievement will be. Therefore, faculty interaction both inside and outside the classroom and high quality college programs and polices reflective of institutional commitment to student learning are positively related to student growth. Astin's Theory of Involvement, unlike traditional pedagogical approaches, focuses on the motivation and behavior of the student. Therefore, all institutional policies and practices can be judged by the degree of involvement they foster in students.

The theory is based on five assumptions. First, involvement requires the investment of psychological and physical energy in objects of one sort or another (such as tasks, people, or activities), whether specific or general. Second, involvement is a continuous concept; different students will invest varying amounts of energy in different objects. Third, involvement has both quantitative and qualitative features. Fourth, the amount of learning or development is directly proportional to the quality and quantity of involvement. Fifth, educational effectiveness of any policy or practice is related to its capacity to induce student involvement [18].

Students learn by becoming involved. The theory of student involvement is grounded in psychoanalysis and classical learning theory. It focuses on a student's commitment to his/her educational goals. Astin [18] described involvement as the quantity and quality of the physical and psychological energy a student devotes to his or her academic experience. It is suggested that educators focus their efforts on what a student does in the classroom and on campus. Involvement occurs along a continuum. The degree of student success in college is directly proportional to the quality and quantity of student involvement with the institution $[18,28]$. The more interaction between students and faculty there is, the more likely it is that a student will have a positive experience $[18,28]$. Students who get involved with college staff and activities tend to have higher retention rates than students who limit their involvement only to classroom learning [18].

Together, Tinto's Theory of Student Departure and Astin's Theory of Involvement frame the conditions that appear to matter the most at community colleges in the U.S. The U.S. Department of Education [98] is promoting a national goal to increase student completion rates by $50 \%$ over the next ten years.

\subsection{Significance}

First year programs that are designed to increase student success have become a prominent feature in higher 
education [3]. The increase of programs aimed at first year students is significantly related to students' academic success [21]. Hendel [30] examined the effects on first semester grades of students participating in learning communities and found that membership in learning communities was positively associated with higher grade point averages. First year experience programs are considered an essential part of ensuring the success of first time in college students [31]. In an effort to encourage more colleges and universities to think about first year experience programs, Reason, Terenzini, and Domingo [31] presented research supporting the importance and impact the first year of college has on a student's overall success.

The costs and other institutional investments make assessment of first year programs and seminars a necessity in higher education and receive attention from a number of stakeholders [3]. No assessment has been done to determine if the SDEV 0170 course has had an impact on student retention at the college of interest, and stakeholders can ask how successful the SDEV 0170 course has been. While there are many questions surrounding the assessment of the SDEV 0170 course, this study focused on retention and academic achievement of first time in college students. The purpose of this study was to look at the college's SDEV 0170 course to examine whether its implementation has any relationship to retention rates and academic achievement of first time in college students. It assessed the Fall 1 cohort of first time in college students in order to examine the fall to spring retention as well as term to term retention. Furthermore, this was the first semester that the SDEV 0170 course was offered both face-to-face as well as online. The study will provide data to inform colleges' decisions to develop an FYE program that is more meaningful, purposeful, and relevant to their organization's mission and commitment to support its students' educational goals.

The FYE program, along with the SDEV 0170 course, may provide a suitable environment for facilitating interventions to improve students' retention and achievement. The SDEV0170 course assists students in identifying campus resources, establishing relationships with other students and with faculty members, and assessing and improving their academic and life management skills [13,32]. Students who have enrolled in a student success course generally earn higher grade point averages, complete a larger number of first-term credit hours, and increase their persistence and graduation rates $[13,32]$. While another component of an FYE program evaluation is assessing the students' needs, this study focused on the general outcome variables of retention and academic achievement. Often programs and services for first-year students are developed but seldom are these programs and services assessed.

\subsection{Literature}

The current trend in higher education matriculation reflects the expanding U.S. college age population. Enrollment in U.S. institutions of higher education rose from 14.5 million students in fall 1993 to 18.5 million in fall 2007. Of the 18.5 million students enrolled in higher education, over 7 million or about $38 \%$ were enrolled in community colleges [33].
Because of increases in the population of 18-year-olds, the number of high school graduates is expected to increase through 2017. The number of high school graduates is projected to increase 6\% between 2005 and 2018 to 3.3 million graduates [33].

According to Census Bureau projections, the number of individuals ages 20-24 is expected to grow from 21.8 million in 2010 to 28.2 million by 2050. From 2010 to 2050, Asians are projected to increase from $4 \%$ to $6 \%$ and Hispanics are projected to increase from $18 \%$ to $37 \%$ of the individuals ages 20-24. During this same period, African Americans are projected to decrease from 15\% to $12 \%$ and whites are projected to decrease from $60 \%$ to $40 \%$ of the individuals ages 20-24 [33].

Because of these demographic changes, postsecondary enrollment is expected to increase $13 \%$ to 20.1 million students in 2017 [33]. Increased enrollment in higher education is projected to come mainly from minority groups, particularly Hispanics. Enrollment of all racial/ethnic groups is projected to increase, but the percentage of whites is projected to decrease from 65\% in 2006 to $61 \%$ in 2017.

College going rates of women are generally considered a mark of success on the path toward gender equity [34]. Unlike the traditional four-year university, the community college opens its doors to all who wish to pursue educational goals. Within the walls of the community college, it is imperative that leaders, support staff, and instructors do all they can to recruit, retain, or transfer students to four-year institutions [35]. Student support services must be comprehensive and flexible in order to reach students of different ages, family circumstances, and ethnic backgrounds [36].

The community college is the primary starting point for minorities in higher education [37]. For many students of color, the community college is their only means of gaining an education and improving their lot in life. As such, the community college must address the specific needs of minority students to assure that they are competitive to continue their higher education or enter the workforce [38].

\subsubsection{Mission of the Community College}

Community colleges are unique institutions of higher education. They are committed to open access and community building. These fundamental values play a major role in the shaping of the role and scope of the American community college [39]. Over time, the question of equity has been raised, as has the question of whether students who are under prepared, low skilled, or learning disabled actually belong in community colleges or if they should be routed to other alternatives such as employment or the military. Community colleges must acknowledge that an open admissions policy is not the same as access and equity. In order to have access and equity, the community college must do more than just simply enroll students, it must provide support services, including counseling, academic advising, and financial aid, helping to ensure that every student has the opportunity to succeed academically [39]. Historically, community colleges have been charged with the task of providing a legitimate entry point to higher education for all students. The mission of the community college can be seen in terms of the different services it provides: career services, 
remedial or developmental education, community education, vocational education, and liberal arts education [39].

\subsubsection{Student Retention}

Student retention is an area of research concerned with understanding the factors that influence student persistence. The literature relating to factors and problems in higher education involving student retention is reviewed here. Every year, a significant number of college students fail to complete their college education. Attrition occurs in a number of ways, some students fail academically, others transfer to another institution, and there are those who withdraw or reduce their course load.

Initial studies on retention were based on psychology, focusing on personal, individual characteristics. Starting in the mid-1970s there was a shift in emphasis from psychology to sociology. Recently, the emphasis centered on the institutional environment and its relationship to students' integration [23]. Much of the literature describes the differences between those students who withdraw from the institution and those who persisted.

While much research has been done to help our understanding of student attrition at institutions of higher education, there is still a need to identify why students drop out or stop out. Understanding student behaviors and explaining retention and attrition rates have continued to be a difficult task. Until the factors influencing student attrition are better understood, retention efforts are likely to have mixed results. At the same time, higher education administrators are seeing increased pressure to explain retention and attrition at their institution of higher education [82].

Retention describes an institution's capacity to keep a student enrolled at the institution, whereas the term persistence describes the student's ability to stay enrolled in the institution. Therefore, retention and attrition represent the institutional view [40]. Attrition focuses on who leaves while the retention focuses on who stays. Just as attrition is the negative view of retention, dropout is the negative way of looking at persistence.

Students are retained if the institution can influence them to re-enroll and students persist if they elect to reenroll [41]. This includes students who transfer to another institution. Students who transfer may achieve their academic goals, but the institution is not able to measure that. For a community college, this is problematic as some transfer students successfully complete their associate's degree prior to transfer. However, many students transfer without completing their degree requirements and this can be viewed as students who leave and do not come back.

Retention is generally measured as enrollment in a subsequent semester. Retention is often what is measured because the focus is on the institution's effort to re-enroll students. In other words, retention is defined as an institution's ability to keep a student from enrollment to commencement [42,43]. Recruitment is an important function of an institution of higher education. However, the retention of students and ultimately the graduation of students is an attribute of excellence for an institution [44]. Of every 100 students entering higher education, roughly 41 will leave the higher education system before earning a college degree [41]. An important component of minority retention is creating an environment in which minority students can flourish. Unlike their White counterparts, many minority college students do not have the luxury of needing only to manage college life as they progress towards a college degree. Colleges and universities need to develop ways to provide institutional support for these students [38]. Improving retention includes developmental courses and strong support student support systems [1].

Higher education must confront the issue of developing strategies for improving student retention. Record numbers of students enrolled in college in the fall of 2011, but the gap between enrollment and completion has led to a focus on improving retention [45]. Institutions of higher education have begun to realize the need to be more responsive to students' needs in order to recruit and retain them [45]. Yet, retention rates have been relatively unchanged, hovering around 67\%. Students are more likely to return for a second year of college at four-year institution, where retention rates were about 74\% in 2011 [45]. Community colleges have shown improvement in retention rates which climbed from 51\% in 2004 to $56 \%$ in 2011 [45]. Taking an internet course is a strong predictor of student retention [1]. The growth in online enrollments in higher education is greatest for nontraditional students at community colleges and that demand for the availability of online courses is expected to continue to grow [46].

However, first semester Hispanic students in online courses reported having difficulty reaching their instructors for help. They also were discovering that they needed the discipline of attending classes on campus [38]. Unfortunately, they discovered this after being enrolled in an online class and often just stopped participating in the online class. Crisp and Nora [47] in referring to the difference in retention rates among diverse student populations, commented that although community colleges provide equality of access to higher education. Many minority students lack financial support and drop out of college when they find a decent paying job. Institutions of higher education that promote academic involvement and social support networks generally experience better persistence among their first year students [41].

White students are more persistent in terms of retention and graduation rates than minority students. Academically they are better prepared, adjust to college life easier, and hail from middle class families [48]. Minorities are often ill equipped academically and financially [47]. Combine these problems with the significant cultural conflict they encounter at predominately white institutions, and the hurdle can be perceived as insurmountable [48]. Many minority students base their decisions about where to attend college on the decisions of friends and siblings [50]. This would suggest that minority students are unlikely to choose to enroll in an institution that has a low minority population. For this reason, social support is imperative for retention of minority students. In fact, studies show that social experiences of minority students in college are more significant in predicting retention than family background and individual characteristics (e.g., [38]). Historically African American colleges or Hispanic serving institutions generally do not have a problem with retention as these students do not feel socially isolated. As a result, minorities at these types of institutions stay in college and are more academically successful [48]. 
National and state reports reflect that minorities are earning less of the degrees awarded by colleges and universities. The most frequently cited hindrances to increasing minority enrollments are often related to environmental conditions, financial constraints, and institutional reputation [50]. The rate of women enrolling in higher education surpasses that of men, resulting in a higher percentage of female students [51]. Increases in higher education enrollment for both women and men are expected to continue by about $16 \%$ for women and $9 \%$ for men by 2018 [52]. The increase in enrollments is not the concern for community college. The concern centers on student persistence and retention.

\subsubsection{Models of Student Persistence and Retention}

Researchers have generated theories of the college student experience that have yielded recommendations aimed at improving retention and graduation rates among college students $[53,54,56]$. These theories can be sorted into the categories of student departure and student success. Student departure theories primarily examine departure from college and make recommendations to reduce departure rates. Student success theories [56] have sought to (a) identify the conditions that foster student success, (b) develop recommendations for policies, programs, and practices to support student success, and (c) propose theoretical frameworks and implementation models to help institutions improve student success rates.

Student departure theories have been criticized because they do not specify how to help students be successful [57]. Student success theories have been criticized for failing to address the complexity of student success, as well as not incorporating the cognitive processes associated with student departure from college. They offer few theoretical models to assist with a definable course of action $[41,56,58]$. Critics of student departure theories and student success theories have called for solutions fitted to individual institutional settings [41,56,58]. In other words, current theory and research have not yet provided institutional leaders with information related to effective programs and policies on student persistence [56].

\subsubsection{Bean and Metzner's Student Attrition Model}

Bean and Metzner [26] proposed an alternative model of college retention. This model suggests that students leaving college are much like employee turnover. This model takes into account external variables and how they can affect the student's attitude and decision. Bean and Nontraditional students are less impacted by on-campus involvement than their traditional peers [26]. Financial issues are a primary concern and students, who perceive financial difficulties, are more likely to leave a college or university [26].

Building on that research, researchers [26] developed a second conceptual model of attrition in which academic, social-psychological, and environmental factors influence socialization factors, which in turn influence dropout syndrome. Dropout is defined as the failure of a student enrolled in the spring semester to re-enroll at the same campus the following fall semester [26]. They believed continued attendance to be a measure of successful socialization. Because Bean and Metzner [26] used dropout syndrome, they did not differentiate between the types of dropout. Unlike Tinto [17] and Spady [59], Bean and Metzer [26] included those who leave involuntarily due to academic dismissal as socialization failures. Thus, they [26] made no distinction between students who voluntarily dropout and those who are forced to leave because of poor performance. They also took a different view of socialization. Bean and Metzer [26] saw the individual actively influencing the process and making choices to determine the outcome.

Later, Bean and Metzer [26] developed a model specifically for nontraditional students at four-year commuter colleges. They recognized the need for a different approach because the level of integration is not the same as residential students in universities. For the nontraditional students, the level of social integration plays a much smaller role.

The term retention describes the institution's ability to keep a student enrolled at the institution, whereas the term persistence describes the student's ability to stay enrolled in the institution. Bean and Metzer [26] focused on student attrition or the lack of persistence based on external variables. The current study is concerned with the institution's retention efforts as it relates to the integration of students into the institution.

\subsubsection{Padilla's Local Model of Successful Minority Students}

Padilla [60] introduced the Local Model of Successful Minority Students in which he identifies factors that enable students to overcome barriers in the college experience. In a ten-year study that focused on successful "Chicano" and other minority students, Padilla [60] identified four barriers to success: (a) discontinuity barriers; (b) barriers that are experienced as lack of nurturing; (c) barriers related to a lack of presence on campus; and (d) resource barriers. For each of these barriers, a successful student must use his or her knowledge combined with the suitable action in order to understand the barrier and to identify the possible solutions to that barrier at the particular institution. With the proper knowledge and solutions, the student is then able to take actions to overcome barriers to success. The model showed how students and institutions are involved in achieving student success. This model offered insight as to why institutions struggle to retain students in that it identified external variables that led to student attrition.

\subsubsection{Rendón’s Model of Validation}

In order to increase retention, higher education must transform its campuses to create a culture of caring and success [58]. In the theory of validation, students are best supported by being provided an array of services that will assist them in making connections with the institution. The validation model is an enabling, confirming, and supportive process supported by in-class and out of class experiences that enhance the academic and personal development of students. The study of student persistence emphasized a holistic approach to working with students [58]. The research has been primarily focused on Hispanic student populations. The college's culture may also impact students in both positive and negative ways [61]. Students often find it difficult to persist in mainstream colleges and universities in part because of inadequacies in the institutional culture. The theory of validation is especially 
well suited to this study as the institution of concern has a Hispanic/Latino enrollment of 53\% [58].

\subsubsection{Astin's Involvement Model}

Astin [18,62] introduced the developmental theory of student involvement, which looked to clearly designate issues that affect student retention in the college environment. In revisiting the theory, he found that students were most impacted by three types of differing aspects of involvement with faculty, with academics, and with peer groups, which according to his observations, are the most influential of the involvement areas [62]. The amount of effort that a student exerts and invests both socially and academically in his or her university experience has a direct relationship with retention [18,62].

An involved student is a student that devotes significant energy to academics, spends considerable time on campus, participates actively in student organizations, and interacts often with faculty [62]. This differs from the role of the student in Astin's earlier input-process-output model [10], where the student is passively developed by the faculty and by university programs. The Theory of Involvement suggests that the student plays an integral role in determining his or her own degree of involvement in college classes, extracurricular activities, and social activities. Of course, the more quality resources available, the more likely those students who are involved will grow or develop. Therefore, faculty interaction both inside and outside the classroom and high quality university programs and policies reflective of institutional commitment to student learning are necessary for student growth.

The quality and quantity of the student's involvement would influence the amount of student learning and development [62]. True involvement requires the investment of energy in academia, relationships, and activities related to the campus. The amount of energy invested will vary greatly depending on student interest and goals, as well as the student commitments. The most important institutional resource, therefore, is student time. The extent to which students can be involved in the educational development is tempered by how involved they are with family, friends, jobs, and other outside activities [62].

Astin [18] developed one of the first and longest lasting models to help in understanding the impact of college on students. This model, known as the Input-EnvironmentOutput Model (I-E-O Model), includes three elements: Inputs, Environment, and Outputs. The concept of involvement theory suggested that students are more likely to have a positive college experience by becoming involved in the college.

The work suggests that students enter college with a preexisting set of characteristics and perceptions that he called the Inputs [18]. These Inputs typically include family background, high school grades, test scores, race, gender, ethnicity, marital status, and their individual reasons for attending the university. The conceptual model indicated that the Input elements not only directly influence the student Outputs, but they also have an effect on the Environment which also influences the student Outputs [10,18].

The second set of elements in the model is Environmental factors, which have an influence on the student's transition experience and on their Outcomes [18] These Environment factors often include the institutional characteristics of the college or university, peer groups, academic major, campus experiences, place of residence, financial aid, and student involvement. The Environmental factors differ based on the students' Inputs and they directly affect the student Outputs.

The final component of the I-E-O Model is regarded as the Outputs. These Outputs can include such things as satisfaction with the college or university environment, student characteristics, beliefs, behavior, academic achievement, academic understanding, abilities, attitudes, career development, and retention $[10,18]$. The model has actually identified 146 possible Input variables; 192 Environmental factors; and 82 Outcome variables [3]. According to the model, these factors interact and create the opportunity for tremendous impact upon students.

In addition to developing a framework to guide research on college students, Astin [18] also developed a Theory of Involvement as a result of his work with longitudinal studies of college student persistence and the important function of higher education as a means of talent development. This theory was developed as a way to explain the dynamic process of change or development, which affects college students [10,13,18,37]. After looking at the factors that affect retention, Astin [18] framed a theory that advanced the concept that students learn by being involved, and as they become involved, they will remain enrolled. Student involvement refers to the extent students are willing to physically and psychologically invest in their academic life [62]. The model suggested a significant predictor of a student remaining at his or her present institution is the level of engagement a student demonstrates [63]. The opposite is also predicted; a student who is not involved is disengaged and is more likely to withdraw from the college or university [18].

\subsubsection{Tinto's Student Integration Model}

The key model for retention was developed by Tinto [2] whose work also supports the importance of student involvement in the transition experience for transfer students. He specifically pointed to the need to understand the connection between student involvement in learning and the resulting impact on persistence.

The student integration model explains the student integration process as a function of academic and social experiences in college [17]. Tinto [17] measured successful academic integration by GPA and social integration by the frequency of positive interactions with peers and faculty in addition to involvement in extracurricular activities. Before they matriculate to postsecondary education, students will develop attributes that are shaped by their familial upbringing. At the same time, they develop academic and social skills and abilities in both formal and informal settings. In turn, these skills and abilities help form students' goals and commitments regarding college, the workforce, and their place in society as a whole. During their time in college, formal and informal college experiences influence the student's level of integration into the college both academically and socially. According to Tinto [17], this level of integration has an impact on the student's development of goals and commitments, which results in a decision to either persist 
in or depart from college. The match between student characteristics and institution, therefore, shapes students' goal commitments, which in turn influence persistence [27].

Students must leave their former communities, if they want to consider themselves part of the community college [41]. The transition stage refers to how students cope with stresses brought on by departing from the familiar, while not completely understanding or integrating into the new college environment. The incorporation stage reflects students' competency as an institutional member. After incorporation, the student is no longer the person he or she once was. This student, in effect, has become a new individual. This view adds a time dimension in the form of longitudinal stages of the integration process that addresses the early stages of separation and transition and difficulties students typically face academically and socially before their incorporation into campus life. Lack of integration into the college campus may also result from students' inability to separate themselves from past associations to make the transition to the new community $[2,27,41]$.

An institutional response to Tinto's [17] work has been to implement structured student support services meant to encourage integration. Community colleges in particular have taken this approach [64]. The underlying assumption is that if colleges provide enough structured opportunities for students to engage with the institution, students will become integrated into the college and persist at higher rates. Studies investigating academic persistence compose one of the most widely reported areas of research in higher education [65]. Tinto is most often cited in and associated with student persistence research [66]. Applying the model to two-year colleges and or commuting students have produced varied results [67]. Some research suggests the model is not relevant. Voorhees [68] found no association between persistence and integration in one community college. Researchers [2,26,70] contended background characteristics and external circumstances have a greater impact on persistence than on-campus factors. Pascarella and Chapmans [24] found community college persistence was influenced by academic integration, not social integration. Later Tinto [70] found classroom involvement not only facilitates academic integration but also promotes integration beyond the classroom. Tinto [17] model has been found to be inadequate for minority students because it assumes disconnection from a home community must occur before integration into a college community can happen [71]. This perspective reinforces the need to understand the experiences of marginalized students, such as two-year college students $[16,61]$. The vast majority of two-year students enroll in community colleges while remaining in their communities of origin, so the issue of separating from a culture of origin is minimal. The dynamics of race, class, and culture have not yet been adequately explored in two-year contexts while utilizing the concept of integration to frame the discussion [67].

Researchers have turned to persistence theory in an attempt to explain and gain an understanding of student departure and persistence patterns. Researcher [2,17] is one of the most notable researchers of persistence. He drew his research from work [59] based on research on suicide [72]. Tinto [41] argued that individual departure from institutions arises from a longitudinal process of interactions between an individual with various attributes, skills, and dispositions (intentions and commitments) and other members of the institutional academic and social systems. According to Tinto's [2,17] theory, the more a student integrates himself or herself into the social and academic life of the campus, the more the student becomes committed to the goal of graduation and develops loyalty to the individual institution. This will increase the chances that students will persist and obtain their degree.

\subsubsection{First Year Experiences Programs}

Evaluation of retention activities, such as FYE programs is essential in light of diminishing financial resources. First year experience programs need to be both effective and efficient [9]. Interventions should be tailored to the institution and evaluated to make sure they are meeting the unique needs of the institution and its students [1].

Research supports the effectiveness of orientation programs in improving retention, degree completion, and academic performance [54]. The positive effects of orientation programs have been reported at both the university and the community college [74]. In response to the growing need to prepare students for their first year of college, institutions of higher education have developed programs and initiatives intended to assist in the transition to higher education. Early efforts took the form of increased institutional resources such as libraries, writing centers, computer labs, or personal computers [10]. Colleges and universities also have offered courses and seminars focused on the development of academic and social skills [74]. Whether courses were offered as formal requirements or optional, they were designed to ease the transition into higher education [74].

Unfortunately, this presents challenges in terms of program evaluation. Colleges and universities vary in many ways, as do the corresponding first year experience programs and course topics. Therefore, evaluation strategies must be developed to suit those particular needs. At the same time, assessment strategies must remain comprehensive and address the first year experience program as a whole. Researchers have recommended that first year experience programs should be evaluated holistically, colleges and universities often focus on the first year population as a whole [75]. They tended to adopt a one size fits all mentality about serving college students [57]. This evaluation approach neglected the ways in which males and females have been shown to differ on many cognitive tasks [34]. In light of the changing demographics, gender continues to emerge as an important issue.

The literature provides supporting theories and explanations for student retention and persistence. However, there is a lack of research on the satisfaction of experiences on campus and even less on the impact of student satisfaction or retention. Research has shown that at-risk populations within higher education may need additional support in order to help them connect with an institution and persist in their education. There is a need for the identification of programs that have demonstrated success in enhancing student persistence and which can be applied to similar populations at other institutions. It 
demonstrates a need for programs that help the increasingly more diverse college student's population transition to higher education. There is a lack of research on retention at community colleges. Further research is needed to define what factors contribute to the success of students who persist as well as transfer to four-year institutions in order to complete their undergraduate studies. Institutions of higher education need to identify programs and strategies that will help at-risk students stay connected with an institution through the completion of a certificate or a degree.

\section{Methodology}

The methodology utilized applies the relationship between first year experience programs and student retention and academic success. Specifically, the study compared academic and retention performance of students in relation to their involvement with a course designed to facilitate the college experience, SDEV 0170. The setting for this study was a community college in central Texas, involving 1557 participants.

The research design involved the analysis of existing transcript data that are maintained by the college. All of the data accessed in order to conduct this study were available through students' transcripts and admissions records. It assessed the Fall 1 cohort of first time in college students in order to examine academic achievement as well as retention. This cohort was selected since this was the first semester that the college offered the SDEV 0170 course as both face-to-face and as an online course. It also examined two demographic characteristics (gender and ethnicity) as to their relationship to student retention and student achievement.

This study examined whether the SDEV 0170 course has any relationship with retention and academic achievement of first time in college students. The research is guided by the following questions:

RQ1: What is the impact of the SDEV 0170 course on achievement of first time in college students at the college?

RQ2: What is the impact of the SDEV 0170 course on retention of first time in college students at the college?

RQ3: What is the difference between 11 week and online courses of SDEV 0170 course on achievement of first time in college students at the college?

RQ4: What is the difference between 11 week and online courses of SDEV 0170 course on retention of first time in college students at the college?

RQ5: How does achievement differ between students who enrolled in the SDEV 0170 course according to gender?

RQ6: How does retention differ between students who enrolled in the SDEV 0170 course according to gender?

RQ7: How does achievement differ between students who enrolled in the SDEV 0170 course according to ethnicity?

RQ8: How does retention differ between students who enrolled in the SDEV 0170 course according to ethnicity?

\subsection{Participants}

The college is a comprehensive community college offering general education, liberal arts and sciences education, vocational/technical education, continuing education, and developmental education programs. The college is an open admission institution, which mirrors the diverse population of a large city in central Texas. With more than $50 \%$ of the student population being comprised of Hispanics, the institution has been identified as a Hispanic Serving Institution. Hispanic Serving Institutions are defined by the U.S. Department of Education as accredited and degree-granting public or private nonprofit institutions of higher education with $25 \%$ or more total undergraduate Hispanic full-time equivalent student enrollment. The defining characteristic of Hispanic serving institutions is its Hispanic enrollment, not its institutional mission.

The participants are comprised of students entering the college for the first time and who have earned less than twelve semester hours. For many students, the choice is not between the community college and a four-year institution, the choice is between the community college and nothing [76]. The college defines a student who has earned less than twelve semester hours and enrolled at the campus for the first time as a first time in college student. At the college of interest, the SDEV 0170 is required for all FTIC students. The participants were composed of those who enrolled and successfully completed an 11 week SDEV 0170 course, or who enrolled and successfully completed an online SDEV 0170 course.

This study involved 1557 participants: 1508 participants in the 11-week SDEV 0170 course; and 48 participants in the online SDEV 0170 course. The study group is comprised of $47 \%$ males, and $53 \%$ females. The participants in the study had an ethnic breakdown of $1.9 \%$ Asian, 4.9\% Black, 23.7\% White, and $61 \%$ Hispanic, with the remaining $5.8 \%$ either unknown or unreported.

\subsection{Variables}

There are five independent variables and two dependent variables.

\subsubsection{Independent Variables}

The first independent variable is the FYE college course (SDEV 0170). The course, SDEV 0170, employs techniques to assist students in gaining the most from their college education. It focuses on both life skills and study skills and includes such topics as familiarity with college regulations, communication and study skills, goal setting, priority management, reading for comprehension, notetaking, test-taking, creativity, establishing relationships, and the power of a positive attitude. The second is the SDEV 11-week course and the third is the 11-week online course. Gender is the fourth independent variable followed by ethnicity as the final one.

\subsubsection{Dependent Variables}

The first dependent variable grade point average (GPA) calculated on a 4-point scale and with students having a $\mathrm{C}$ or better in the course. The second variable is retention, involving students enrolled in a given fall semester who re-enroll the next Spring semester, or the students enrolled in a given Spring semester who re-enroll the next Fall semester [77].

\subsection{Data Collection}


All of the data was obtained from transcript and admissions records. The college of interest uses a major student registration and information system, which integrates information from various students' processes into a centralized location. Quantitative data on achievement, as measured by grade point average, and retention, as measured by the students' enrollment in the subsequent semester, were analyzed to examine if relationship exists between the SDEV 0170, retention, and success.

\subsection{Data Analysis}

A series of statistical analyses were used to calculate results. Analysis of Variance and post hoc analyses were performed as well as bivariate correlations. The study was ex post facto, using a causal comparative design. The data were obtained by running a report from the colleges' student registration and information system.

\section{Results}

Data from four consecutive academic terms were used in analyses. For ease of interpretation they are referred to in consecutive order as: Fall 1; Spring 2; Fall 3; and Spring 4.

\subsection{Research Question One}

What is the impact of the SDEV 0170 course on achievement of first time in college students at the college? To address research question one, an analysis of the characteristic present group was performed. For the Fall 1 term the impact of the SDEV 0170 course was statistically significant with achievement (GPA for Fall 1: failed course $M=1.27$; passed course $M=3.10)$ at $F(1,1556)=$ $740.67, p<.001$. For following term, Spring 2, the impact of the SDEV 0170 course was statistically significant with achievement (GPA for Spring 2: failed course, $\mathrm{M}=1.65$; passed course, $\mathrm{M}=2.68)$ at $\mathrm{F}(1,1277)=79.29, p<.001$. For following fall term, Fall 3, the impact of the SDEV 0170 course was statistically significant with achievement (GPA for Fall 3: failed course, $M=2.07$; passed course, $\mathrm{M}=2.77)$ at $\mathrm{F}(1,945)=24.52, p<.001$. For next spring term, Spring 4, the impact of the SDEV 0170 course was statistically significant with achievement (GPA for Spring 4 , failed course $\mathrm{M}=2.12$; passed course, $\mathrm{M}=2.74)$ at $\mathrm{F}(1$, $841)=16.95, p<.001$.

Since achievement according to GPA showed lower mean scores from term to term, a one-tailed correlation was run to indicate if there was a trend. FrankforNachmais (1999) considered correlations coefficients to be (a) weak $(\mathrm{r}=.22)$, moderate $(\mathrm{r}=.52)$ and (c) strong ( $\mathrm{r}$ $=.82$ ). Results showed statistical significance for students who passed the SDEV 0170 course in the Fall 1 (GPA for Fall 1: failed course $M=1.27$; passed course $M=3.10$ ) to Spring 2 (GPA for spring: failed course, $M=.85$; passed course, $\mathrm{M}=2.35), r=.49, p<.001$. Results showed statistical significance for students who passed the SDEV 0170 course in the Fall 1 term (GPA for Fall 1: failed course $M=1.27$; passed course $M=3.10$ ) to the Fall 3 term (GPA for Fall 3: failed course, $M=.60$; passed course, $\mathrm{M}=1.86), r=.39, p<.001$. Results showed statistical significance for students who passed the SDEV
0170 course in the Fall 1 term (GPA for Fall 1: failed course, $M=1.27$; passed course $M=3.10$ ) to the final spring term, Spring 4 (GPA for Spring 4, failed course M $=.60$; passed course, $\mathrm{M}=1.60), r=.32, p<.001$. As students moved through the program, GPAs declined.

\subsection{Research Question Two}

What is the impact of the SDEV 0170 course on retention of first time in college students at the college? To answer research question two, an analysis of the characteristic present group was performed based on retention (returned; not returned), an ANOVA was used to examine the relationship between the SDEV 0170 course and retention. For the spring term the impact of the SDEV 0170 course was statistically significant with retention (enrollment for Spring 2: failed course, $\mathrm{M}=.51$; passed course $\mathrm{M}=.87)$ at $\mathrm{F}(1,1556)=196.81, p<.001$. For the next term, Fall 3, the impact of the SDEV 0170 course was statistically significant with retention (enrollment for Fall 3: failed course, $M=.29$; passed course $M=.67$ ) at $\mathrm{F}(1,1556)=128.49, p<.001$. For Spring 4 term the impact of the SDEV 0170 course was statistically significant with retention (enrollment for spring: failed course, $\mathrm{M}=.28$; passed course $\mathrm{M}=.59$ ) at $\mathrm{F}(1,1556)=$ $77.0, p<.001$. Results showed statistical significance for students who passed the SDEV 0170 course in Fall 1, for enrollment from Spring 2 (enrollment for Spring 2: failed course, $\mathrm{M}=.51$; passed course $\mathrm{M}=.87$ ) to Fall 3 (enrollment for Fall 3: failed course, $\mathrm{M}=.29$; passed course $\mathrm{M}=.67$ ) $, r=.37, p<.001$.

Results also showed statistical significance for students who passed the SDEV 0170 course in the Fall 1, for enrollment from Spring 2 (enrollment for Spring 2: failed course, $\mathrm{M}=.51$; passed course $\mathrm{M}=.87$ ) to Spring 4 (enrollment for Spring 2: failed course, $\mathrm{M}=.28$; passed course $\mathrm{M}=.59), r=.32, p<.001$. As students moved through the program retention fell.

Results showed statistical significance for students who passed the SDEV 0170 course in the Fall 1, for enrollment from Fall 2 (enrollment for Fall 2: failed course, $M=.29$; passed course $M=.67$ ) to Spring 4 (enrollment for Spring 4: failed course, $\mathrm{M}=.28$; passed course $\mathrm{M}=.59$ ), $r=.65$, $p<.001$. Again, as students moved through the program retention fell.

Results also showed statistical significance for students who failed the SDEV 0170 course in the Fall 1, for enrollment from Spring 1 (enrollment for Spring 1: failed course, $\mathrm{M}=.51$; passed course $\mathrm{M}=.87$ ) to Fall 2 (enrollment for Fall 3: failed course, $\mathrm{M}=.29$; passed course $\mathrm{M}=.67), r=.45, p<.001$. Results showed statistical significance for students who failed the SDEV 0170 course in the Fall 1, for enrollment from Spring 1 (enrollment for Spring 1: failed course, $\mathrm{M}=.51$; passed course $\mathrm{M}=.87$ ) to Spring 2 (enrollment for Spring 2: failed course, $\mathrm{M}=.28$; passed course $\mathrm{M}=.59$ ), $r=.47, p$ $<.001$. Once again, as students moved through the program retention fell.

Results showed statistical significance for students who failed the SDEV 0170 course in the Fall 1, for enrollment from Fall 2 (enrollment for Fall 2: failed course, $M=.29$; passed course $M=.67$ ) to Spring 2 (enrollment for Spring 2 : failed course, $\mathrm{M}=.28$; passed course $\mathrm{M}=.59$ ), $r=.61$, $p<.001$. As students moved through the program retention fell. 


\subsection{Research Question Three}

What is the difference between 11 week and online courses of SDEV 0170 course on achievement of first time in college students at the college? An analysis of the characteristic present group was performed. An ANOVA was performed to examine the relationship between the SDEV 0170 face to face and online course and retention. For Fall 1 the impact of the method of instruction (on campus vs. online) for the SDEV 0170 course was not statistically significant with achievement (GPA for Fall1: face-to-face, $\mathrm{M}=2.84$; online, $\mathrm{M}=2.80$ ) at $\mathrm{F}(1,1556)$ $=.05, p=.82$. For Spring 2 the impact of method of instruction for the SDEV 0170 course was not statistically significant with achievement (GPA for Spring 2: face-toface, $\mathrm{M}=2.59$; online, $\mathrm{M}=2.51)$ at $\mathrm{F}(1,1276)=.16, p$ $=.69$. For Fall 2 the impact of method of instruction for the SDEV 0170 course was not statistically significant with achievement (GPA for Fall 2: face-to-face, $\mathrm{M}=2.72$; online, $\mathrm{M}=2.93$ ) at $\mathrm{F}(1,954)=.85, p=.36$. For Spring 4 the impact of method of instruction for the SDEV 0170 course was not statistically significant with achievement (GPA for Spring 4: face-to-face, $\mathrm{M}=2.69$; online, $\mathrm{M}=$ 2.76) at $\mathrm{F}(1,841)=.84, p=.77$.

\subsection{Research Question Four}

What is the difference between 11 week and online courses of SDEV 0170 course on retention of first time in college students at the college? An ANOVA was performed to examine the relationship between the SDEV 0170 face-to-face and online courses and retention. For Spring 2 the impact of the teaching method of the SDEV 0170 course was not statistically significant with retention (enrollment for Spring 2: face-to-face, $\mathrm{M}=$.82; online, $\mathrm{M}$ $=.75)$ at $\mathrm{F}(1,1556)=1.69, p=.19$. For Fall 3 the impact of the SDEV 0170 course was not statistically significant with retention (enrollment for Fall 3: face-to-face, $\mathrm{M}=.62$; online, $\mathrm{M}=.50)$ at $\mathrm{F}(1,1556)=2.72, p=.10$. For Spring 4 the impact of the SDEV 0170 course was not statistically significant with retention (enrollment for Spring 4: faceto-face, $\mathrm{M}=.54$; online, $\mathrm{M}=.48)$ at $\mathrm{F}(1,1556)=77.0, p$ $=.38$.

\subsection{Research Question Five}

How does achievement differ between students who enrolled in the SDEV 0170 course according to gender? An ANOVA was used to examine the relationship between the SDEV 0170 course and gender on achievement. For Fall 1 the impact of gender and the SDEV 0170 course was not statistically significant with achievement (GPA for Fall 1: female $\mathrm{M}=2.88$; male $\mathrm{M}=$ 2.78) at $\mathrm{F}(1,1556)=2.94, p=.09$. For Spring 2 the impact gender and the SDEV 0170 course was statistically significant with achievement (GPA for Spring 2: female $\mathrm{M}=2.71$; male $\mathrm{M}=2.46)$ at $\mathrm{F}(1,1276)=12.08, p<.01$. For Fall 3 the impact of gender and the SDEV 0170 course was statistically significant with achievement (GPA for Fall 3: female $M=2.82$; male $M=2.61$ ) at $F(1$, $954)=8.27, p, .01$. For Spring 4 the impact of gender and the SDEV 0170 course was not statistically significant with achievement (GPA for Spring 4: female $\mathrm{M}=2.72$; male $\mathrm{M}=2.66)$ at $\mathrm{F}(1,841)=.65, p=.42$.

\subsection{Research Question Six}

How does retention differ between students who enrolled in the SDEV 0170 course according to gender? For Spring 2 the impact of the SDEV 0170 course and gender was not statistically significant with retention (enrollment for spring 2011: female, $\mathrm{M}=.81$; on-line, $\mathrm{M}$ $=.83)$ at $\mathrm{F}(1,1556)=1.17, p=.28$. For Fall 3 the impact of the SDEV 0170 course and gender was not statistically significant with retention (enrollment for fall 2011: female, $\mathrm{M}=.60$; on-line, $\mathrm{M}=.62)$ at $\mathrm{F}(1,1556)=.62, p=.43$. For Spring 4 the impact of the SDEV 0170 course and gender was not statistically significant with retention (enrollment for Spring 4: female, $\mathrm{M}=.54$; on-line, $\mathrm{M}$ $=.54)$ at $\mathrm{F}(1,1556)=.02, p=.89$.

\subsection{Research Question Seven}

How does achievement differ between students who enrolled in the SDEV 0170 course according to ethnicity? Although American Indian was a category for ethnicity, it was dropped from the analysis because of too few cases $(\mathrm{N}=4)$. Since unknown was not a category for ethnicity, it was dropped from the analysis because ethnicity was not reported $(\mathrm{N}=112)$. For Fall 1 the impact of the SDEV 0170 course and ethnicity was statistically significant with achievement (GPA for Fall 1: Asian, $\mathrm{M}=3.29$; Black, $\mathrm{M}$ = 2.79; Hispanic, $\mathrm{M}=2.78$; White, $\mathrm{M}=2.65)$ at $\mathrm{F}(3,1440)$ $=5.17, p<.01$. For Spring 2 the impact of the SDEV 0170 course and ethnicity was statistically significant with achievement (GPA for Spring 2: Asian, $\mathrm{M}=3.16$; Black, $\mathrm{M}=2.45$; Hispanic, $\mathrm{M}=2.52$; White, $\mathrm{M}=2.73)$ at $\mathrm{F}(3$, $1188)=4.36, p<.01$. For Fall 3 the impact of the SDEV 0170 course and ethnicity was statistically significant with achievement (GPA for Fall 3: Asian, $\mathrm{M}=3.12$; Black, $\mathrm{M}$ $=2.61$; Hispanic, $\mathrm{M}=2.67$; White, $\mathrm{M}=2.87)$ at $\mathrm{F}(3,884)$ $=3.24, p<05$. For Spring 4 the impact of method of instruction for the SDEV 0170 course was statistically significant with achievement (GPA for Spring 4: Asian, M = 3.16; Black, $\mathrm{M}=2.55$; Hispanic, $\mathrm{M}=2.64$; White, $\mathrm{M}=$ 2.82) at $\mathrm{F}(3,782)=2.98, p<.05$.

For Fall 1, the impact of the SDEV 0170 course and ethnicity was statistically significant with achievement. A post hoc comparison using the Tukey HSD test indicated that the mean score for achievement of Asians $(M=3.29$, $\mathrm{SD}=.86)$ were significantly different from Blacks $(\mathrm{M}=$ $2.79 \mathrm{SD}=1.09)$ and Hispanics $(\mathrm{M}=2.78, \mathrm{SD}=1.13)$. The mean score for achievement of Whites $(M=3.0$, SD $=1.12)$ and Hispanics $(\mathrm{M}=2.78, \mathrm{SD}=1.13)$ were also found to be significantly different.

For Spring 2, the impact of the SDEV 0170 course and ethnicity was statistically significant with achievement. A post hoc comparisons using the Tukey HSD test indicated that the mean score for achievement of Asians $(\mathrm{M}=3.15$, $\mathrm{SD}=.95)$ was significantly different from Blacks $(\mathrm{M}=$ $2.45 \mathrm{SD}=1.24)$ Hispanics $(\mathrm{M}=2.52, \mathrm{SD}=1.23)$. The mean score for achievement of Whites $(\mathrm{M}=2.73, \mathrm{SD}=$ 1.24) and Hispanics $(\mathrm{M}=2.52, \mathrm{SD}=1.23)$ were also found to be significantly different.

For Fall 2, the impact of the SDEV 0170 course and ethnicity was statistically significant with achievement. A post hoc comparisons using the Tukey HSD test indicated that the mean score for achievement of Asians $(\mathrm{M}=3.12$, $\mathrm{SD}=1.19)$ was significantly different from Hispanics (M $=2.66, \mathrm{SD}=1.10)$. The mean score for achievement of 
Whites $(\mathrm{M}=2.87, \mathrm{SD}=1.16)$ and Hispanics $(\mathrm{M}=2.66$, $\mathrm{SD}=1.10$ ) were also found to be significantly different.

For Spring 4, the impact of method of instruction for the SDEV 0170 course was statistically significant with achievement. A post hoc comparisons using the Tukey HSD test indicated that the mean score for achievement of Asians $(\mathrm{M}=3.07, \mathrm{SD}=1.22)$ was significantly different from Blacks $(\mathrm{M}=2.46, \mathrm{SD}=1.29)$ and Hispanics $(\mathrm{M}=$ 2.62 , SD $=1.14)$. The mean score for achievement of Whites $(\mathrm{M}=2.82, \mathrm{SD}=1.20)$ and Hispanics $(\mathrm{M}=2.62$, $\mathrm{SD}=1.14$ ) were also found to be significantly different.

\subsection{Research Question Eight}

How does retention differ between students who enrolled in the SDEV 0170 course according to ethnicity? An ANOVA was performed to examine the relationship between the SDEV 0170 course and ethnicity with retention. For Spring 2 the impact of the SDEV 0170 course and ethnicity was not statistically significant with retention (enrollment for Spring 2: Asian, $\mathrm{M}=.93$; Black, $\mathrm{M}=.77$; Hispanic, $\mathrm{M}=.83$; White, $\mathrm{M}=.83)$ at $\mathrm{F}(3,1440)$ $=1.46, p=.22$. For Fall 3 the impact of the SDEV 0170 course and ethnicity was statistically significant with retention (enrollment for Fall 3: Asian, $\mathrm{M}=.87$; Black, $\mathrm{M}$ $=.51$; Hispanic, $\mathrm{M}=.62$; White, $\mathrm{M}=.60)$ at $\mathrm{F}(3,1440)=$ 4.26, $p<.01$. For Spring 4 the impact of the SDEV 0170 course and ethnicity was statistically significant with retention (enrollment for Spring 4: Asian, $\mathrm{M}=.80$; Black, $\mathrm{M}=.50$; Hispanic, $\mathrm{M}=.55$; White, $\mathrm{M}=.52)$ at $\mathrm{F}(3,1440)$ $=3.24, p<.05$.

For Fall 2, the impact of the SDEV 0170 course and ethnicity was statistically significant with retention. A post hoc comparisons using the Tukey HSD test indicated that the mean score for the retention of Asians $(\mathrm{M}=.87$, $\mathrm{SD}=.35)$ was significantly different from Blacks $(\mathrm{M}=51$, $\mathrm{SD}=50)$, Hispanics $(\mathrm{M}=.32, \mathrm{SD}=.49)$ and Whites $(\mathrm{M}$ $=.60, \mathrm{SD}=49)$. For spring Spring 4 , the impact of the SDEV 0170 course and ethnicity was statistically significant with retention. A post hoc comparisons using the Tukey HSD test indicated that the mean score for retention of Asians $(\mathrm{M}=.80, \mathrm{SD}=.41)$ was significantly different from Blacks $(\mathrm{M}=50, \mathrm{SD}=50)$, Hispanics $(\mathrm{M}$ $=.55, \mathrm{SD}=.50)$ and Whites $(\mathrm{M}=.52, \mathrm{SD}=50)$.

\section{Discussion}

First year experience programs that are designed to increase student success have become a prominent feature in higher education [3]. The increase of programs aimed at first-year students is due to studies showing that participation in first-year programs is significantly related to students' academic success [21]. The results of this study might be useful in identifying possible areas of improvement for the SDEV course and the overall FYE program.

The costs and other institutional investments make assessment of first year programs and seminars a necessity in higher education, yet the programs receive attention from a number of stakeholders [3]. Although programs and services for first-year students are often developed, they are seldom assessed. The purpose of this study was to assess the college's SDEV 0170 course to examine whether its implementation has any relationship to retention rates and academic achievement of first time in college students.

\subsection{Conclusions}

Assessment of first year experience programs is a pressing concern of higher education. There is an ongoing need for data on what makes an effective FYE program especially within a community college setting. The findings in this study highlight the importance of assessing FYE programs, especially the curriculum of a development course, such as the SDEV 0170 course. The Tinto $[2,41]$ focused considerable attention on institutional fit as a factor in student retention. His general departure models emphasized the importance of the academic and social integration experienced by the student. First year experience programs are designed to assist students with this integration by helping students feel better prepared to begin college and by helping students develop a connection to the college through meaningful relationships with faculty and other students. Therefore, assessing FYE programs for their effectiveness cannot be overemphasized. Tinto's model $[2,41]$ validates the need for schools to assume a proactive role in a student's integration process. Students who successfully completed the course may have been assisted in the following: (a) making the transition from high school to college; (b) being introduced to the services and culture of the college; and (c) integrating into an intellectual community of students and faculty.

Institutions of higher education need to examine the factors that contribute to the early departure of its students in order to decide which programs or courses of action would best serve its students [29]. The research on student retention is centered on persistence or departure models [25,31,70]. Orientation and other FYE programs are designed to support first time in college students [55,78]. Although FYE programs have achieved varying degrees of success, Upcraft, Gardner, and Barefoot [3] noted that overall the dropout rate has held steady. Perhaps this rate would be even higher without the intervention FYE programs provide. Researchers [79] identified the need for programs that teach decision-making skills, encourage self-advocacy, provide rigorous curriculum advising, and provide services that support students during their first year. These are the skills taught in SDEV 0170 course.

First year experience programs need to be both effective and efficient [9]. The environment of education is changing with the increasing popularity of online instruction. Developments in distance education have led to questions about the effectiveness of this method of educational delivery and the conditions that make it a successful experience for learners [80]. Researchers [1] stated that taking an internet course is a strong predictor of student retention. Allen and Seaman [46] noted that the growth in online enrollments in higher education is most prominent for nontraditional students at community colleges and that demand for the availability of online courses is expected to continue to grow. Workman and Stenard [81] analyzed the needs of distance learners and identified five specialized needs: (a) clarity of online programs, policies, and procedures; (b) self-esteem; (c) identifying with the school; (d) social integration; and (e) access to support services. The SDEV course specifically 
addresses two of these needs. The course addresses the need to feel an identity with the school so students do not view themselves as outsiders. This need is closely related to sense of community, which Tinto $[2,41]$ refers to as institutional commitment.

As budgets become tighter and accountability demands from political bodies and accrediting agencies grow [82], it is reasonable to assume that so too will the need to justify the effectiveness of FYE programs. This study found that the SDEV 0170 course has had an impact on academic success and student retention at the college of interest. The FYE program, specifically the SDEV 0170 course, may provide a suitable environment for facilitating interventions to improve students' retention and achievement. Both the face-to-face and online SDEV 0170 course are designed with very specific course content and objectives. The course focuses on college resources, time management, note taking, degree plans, campus culture, career exploration, and college policies and procedures. The goal of the course is to provide the student with skills and knowledge about the institution. The course, which is designed to assist students in their academic and social development in addition to their transition to college, may help to reduce the barrier that online classes tend to present. Whether FYE programs are designed for face-toface, online, or a combination of the two, they must ensure effectiveness in order to address demands from those who govern public institutions.

The course is offered as a formal requirement and is designed to ease the transition into higher education. White, Goetz, Hunter, and Barefoot [75] were among the first researchers to describe the FYE intervention strategy for incoming first year students. The research focused not only on the assessment of first-year students' skills and their success, but also on the design and implementation of FYE programs. First year experiences should afford students opportunities to interact socially (with peers and faculty) as well as introduce students to academic facilities, counseling staff, and other faculty during advising sessions [75]. Typically, postsecondary education persistence studies find that academic integration has an important impact on persistence [10]. Consequently, persistence is often viewed as a measure of how well students integrate into a particular school. The student integration model explains the student integration process as mostly a function of academic and social experiences in college $[2,41]$. Tinto $[2,41]$ measured successful academic integration by grade point average (GPA) and evaluated social integration by the development and frequency of positive interactions with peers and faculty and involvement in extracurricular activity. The study did not support the idea that gender affects retention or GPA, however it did support the idea that students are likely to remain enrolled in college, if they are integrated socially and academically into the institution.

There is evidence of a growing gender gap as females participate and persist in education at higher rates than their male counterparts do [83]. In 2010, as in every year since 1980, a lower percentage of male than female 18 to 24 year olds enrolled in college. In addition to college enrollment differences, there are gaps in postsecondary attainment for males and females. Among first time in college students seeking bachelor's degrees who started full time at a 4-year college, a higher percentage of females than males completed bachelor's degrees within 6 years. This pattern was seen across all ethnic groups [83]. This study looked at the college's effort to integrate students to the college with the SDEV course. Results indicate the course minimizes retention differences between males and females.

Tinto [2,41] is most often cited in and associated with student persistence research [66]. Tinto [2,41] framework has been applied to numerous studies of student persistence in higher education. However, its usefulness for community college students has been questioned. Community college persistence was influenced by academic integration, not social integration [2,41]. Rendon, Jalomo, and Nora [61] observed that the model is based on the acculturation/assimilation theories developed during the 1960s. According to the theory, it was considered the responsibility of students in college, like minorities in society, to assimilate to the culture of the college. Applying the model to two-year colleges and commuting students has produced mixed results [67]. There is an assumption that community colleges fail to provide students with opportunities for social integration or that the social aspect of higher education may be less appealing to students attending two-year commuter institutions [64]. Studies show that social experiences of minority students in college are more significant in predicting retention than family background and individual characteristics [38]. Historically, African American colleges or Hispanic Serving Institutions generally do not have a problem with retention, as these students do not feel socially isolated. As a result, they stay in college and are more successful academically [48].

Community colleges often are assumed a safe place for at risk students to pursue higher education [84]. Jones and Becker [79] identified the need for programs that teach decision-making skills, encourage self advocacy, provide rigorous curriculum advising, and provide services that support students during their first year. The issue here may be academic preparedness; Hispanics tend to be firstgeneration students and are likely to enter college with less academic preparation, and to have limited access to information about the college experience, either firsthand or from relatives [85]. Academic preparation of Hispanics is lacking on average, as Hispanics score lower on standardized college admission tests, and require remedial English and mathematics compared to white students [86]. Only $20 \%$ of all African-American students and 16\% of Hispanic students leave high school ready for college [87].

A post hoc comparison showed that the mean score for the retention of Asians was significantly different from Blacks, Hispanics, and Whites. The community college is the primary starting point for minorities in higher education [37]. Students who passed the course as opposed to students who failed the course had higher retention rates. Asians in particular had higher GPAs along with higher retention rates. Rendon [58] suggested that in order to increase retention, higher education must transform its campuses to create a culture of caring and success. In the theory of validation [61], students are best supported by being provided an array of services that will assist them in making connections with the institution. This will increase the chances that the student will persist.

Higher education enrollment rates are generally lower for African Americans and Hispanics when compared to 
Whites and Asians [83]. Across ethnic groups, the percentages of African Americans and Hispanic full-time students at 4-year institutions who attained bachelor's degrees were lower than the percentages of White and Asian students who attained a bachelor's degree [88]. Asian students were also found to be more likely to participate in clubs than Hispanic, Black or White students [88]. According to Tinto's [2,41] theory, the more a student integrates him or herself into the social and academic life of the campus, the more the student becomes committed to the goal of graduation and develops loyalty to the individual institution. The degree of student success in college is directly proportional to the quality and quantity of student involvement with the institution $[19,28]$.

\subsection{Implications}

In an effort to increase student retention, institutions of higher education have introduced a number of retention strategies, one of which is the first year experience course. The course is designed to enhance academic and social integration among first year college students. Pascarella and Terenzini [10] looked at the relationship between integration and commitment and found that academic integration was related to institutional commitment. The SDEV 0170 course is a one semester credit hour course required for all first time in college students and those transferring from other institutions who have earned less than 12 semester hours.

Females, minorities, and older students have been entering higher education at a rapidly increasing rate [89]. Additionally, at-risk populations within higher education may need additional support in order to help them connect with an institution and persist in their education. The SDEV 0170 course is for new students transitioning to college. The course includes, but is not limited to the following topics: college resources, time management, note taking, degree plans and transfer strategies, campus culture, career exploration, and college policies and procedures. This allows students to gain skills and knowledge about the institution, and the skills that will help the student to be a competent member of the institution [9, 70]. However, this study did not take into account the ways in which males and females have been shown to differ on cognitive tasks [34].

Retaining current students, as opposed to recruiting new ones, is generally considered an economically sensible strategy. An estimated one third of college students do not complete a degree, and most of them leave within their first year of college [8]. Lower graduation rates due to attrition are costly to colleges and universities which lose large amounts of money when enrollment is reduced $[2,7,9]$. Beyond the financial considerations, institutions of higher education, especially community colleges with their open enrollment policies, have made an implicit commitment to students to provide them with intellectual and social development [2,10,54]. First year seminars, such as the SDEV 0170 course, aim to assist students in their academic and social development in addition to their transition to college. They also help institutions of higher education meet retention goals [11].

Gender was selected as a demographic characteristic because a statistical correlation between gender and first semester GPA has been shown in previous research [7]. Females have made notable gains in higher education enrollments. In order to establish a more complete understanding of female students in higher education, researchers must examine the representation of female students, their academic success, retention rates in addition to their representation in other areas of student life [91]. With regard to gender the SDEV 0170 course may provide a suitable environment for facilitating interventions to improve students' retention and achievement for both males and females. The course content appears to support both male and female students in identifying campus resources, establishing relationships with other students and with faculty members, and improving their academic and life management skills, all of which are consider important to academic success and retention $[13,28]$.

This study found that ethnicity made a difference, which indicates that cultural values may influence GPA and retention. However, the dynamics of race, class, and culture have not yet been adequately researched in community college settings utilizing Deil-Amen's [67] concept of integration. The model has been found to be inadequate for minority students because it assumes disconnection from a home community must occur before integration into a college community can happen [71]. The vast majority of community college students enroll in classes while remaining in their communities of origin, so the issue of separating from a culture of origin is minimal. In addition to academic and social involvement Pascarella and Terenzini [10] also identified several other variables that influence the transition to higher education such as family background, socioeconomic standing, and academic preparation. Astin [62] identified involvement with faculty as one of the three most influential forms of involvement along with academic and social involvement.

In response to the growing need to prepare students for their first year of college, institutions of higher education have developed programs and initiatives intended to assist in the transition to higher education. There is a need for the identification of programs that have demonstrated success in enhancing academic success and retention, which can be applied to similar populations at other institutions. Lower graduation rates due to attrition are costly $[2,7,90]$. In addition to the financial considerations, community colleges with their open enrollment policies have made an implicit commitment to students to provide them with intellectual and social development [10,54,70].

\subsection{Recommendations and Future Research}

The study focused on the academic success and retention of first time in college students from Fall 1 to the Spring 4 and what role the SDEV 0170 course may have had in increasing academic success and retention for that group. The following recommendations are based on the literature, theory, and results of the study as an FYE program utilizing the SDEV 0170 course.

\subsubsection{Recommendations}

Neither the instructional experience of the SDEV 0170 instructors nor the consistency with which the SDEV 0170 course was presented was considered in this study. Several researchers $[53,57,92,93]$ noted that quality of instruction 
was a factor used by students to judge their experience with the institution. Therefore, quality of instruction and consistency in the content of SDEV 0170 course could be considered a key component in student retention since the SDEV 0170 course is usually the student's first exposure to the campus and classroom environment.

Other factors of student retention discussed in the literature review should be incorporated into a thorough assessment of FYE programs. These include student characteristics [2,76]; external forces [2,94]; academic advising [54,92]; and student accountability [92,94]. Only by gathering specific data on its students can an institution design the most effective retention program. An institution must define its purpose for assessing an FYE program prior to designing a research plan and selecting an appropriate methodology.

Although the students who passed the course had persisted term to term more than those who failed the course, the results of this study showed that student overall GPA declined over time. The fact that this is a one-hour credit course may mean that the course does not provide enough time to integrate students academically and socially to the institution. In order to identify trends in the academic success of the students who completed the SDEV course, future studies may compare recent cohorts of first time in college students at the college. Follow-up studies may also evaluate differences among completers and nonparticipants' academic performance, persistence, and graduation rates from year to year.

Further research is required to define what factors contribute to the success of students who persist and transfer to four-year institutions in order to complete their undergraduate studies. Institutions of higher education need to identify programs and strategies that will help atrisk students stay connected with an institution through the completion of a certificate or a degree.

\subsubsection{Future Research}

Finally, there are several issues raised for future research. First, future research regarding academic success and retention of first time in college students who complete SDEV 0170 may help the college understand the degree to which students are socially integrated in addition to their academic performance, persistence, and graduation rates. By comparing the social integration of SDEV 0170 completers to their non-completer counterparts, the college may determine that SDEV 0170 course completers are more socially integrated. If course completers are more socially integrated, it would provide important data for designing programs to help those students who are less socially integrated to become more socially integrated, hopefully leading to higher retention rates.

Second, the study showed that GPAs changed from semester to semester. Future research should look the changes in GPA to see if they are significant. If so, it can help inform changes in the SDEV 0170 course or FYE experiences on campus. Pascarella and Terenzini [10] noted that GPA is one of the most important factors for a student's persistence in college. What research lacks is an understanding of how changes in GPA affect retention. This study showed that as students continued from term to term, their GPA declined. Further research could examine if a statistically significant drop in GPA affects persistence.
Third, since there were no differences in online and face-to-face courses, other studies could look at course quality. The SDEV 0170 course focuses on the process of integration both academically and socially. This may help overcome the isolation, which is believed to decrease student persistence in online courses [95]. This study showed no statistical significance between online and face-to-face instruction. Further research could examine if enrollment in an online course as opposed to a fully online program has a statistically significant effect on GPA and retention.

Fourth, a comparison should be done between those students who take FYE courses and those who do not. Comparisons should be longitudinal and can be made for choice of major, GPA, retention, and graduation. Significant portions of the community college population enroll in vocational education programs, and thus, community college programs prepare much of the nation's workforce [96]. Further research could examine if enrollment in and completion of an SDEV course has statistically significant effects on graduation rates.

Fifth, a study should be done to look at how many students who complete an FYE program at a community college continue to 4-year institutions. This also can include tracking their GPAs, retention rates, and graduation rates. The transfer function is a primary concern of the community college. A core indicator typically used to assess the transfer function is the number of students who transfer in a given year [97]. Further research could examine if enrollment in and completion of an SDEV course has statistically significant effect on graduation or transfer rates.

Finally, a comparison can be done of those students who complete an SDEV course and go on to a 4-year institution as to whether they have a higher graduation rate than those who started at a 4-year institution. Another core indicator typically used to assess the transfer function is the academic performance of students after they transfer [97]. Additional research would help in the understanding of transfer function between community colleges and four-year institutions. Further research could examine if a difference in academic performance exists among students who complete a FYE course at one institution and then transfer to another institution.

\section{Summary}

Although FYE programs have achieved varying degrees of success, Upcraft, Gardner, and Barefoot [3] noted that overall the dropout rate, as reported by the American College Testing Program, has held steady at around 33\% over several years. Perhaps this rate would be even higher without intervention FYE programs. First year seminars seek to help the university or college meet persistence and graduation goals [11]. Successful first-year experience programs are supported by an outcome assessment process that is strongly connected to the FYE program goals [13].

This study examined the possible effect of the Student Development Course SDEV 0170 on retention and academic achievement. It also examined instructional methods (face-to-face and online) and two demographic characteristics (gender and ethnicity) as to their relationship to student retention and academic 
achievement. The study used pre-existing data from the Community College District student information database. The SDEV 0170 course employs techniques to assist students in gaining the most from their college education. This course is intended to provide the student with skills necessary to assume responsibility for individual learning.

This study found the impact of the SDEV 0170 course was statistically significant with retention and achievement as measured by GPA. When academic and environmental variables are positive, students should succeed and persist. When both variables fail to support students, they are likely to have lower GPAs and are less likely to persist. When academic variables are positive, but environmental variables are negative, the favorable effects of academic variables on student goal attainment are suppressed or diminished. Students' academic success may decline over time despite strong academic performance, if they perceive low levels of utility, satisfaction, or goal commitment, or if they experience high levels of stress [10]. Nevertheless, if students are to succeed, programs and services must be made available for them to transition to college, to introduce them to the services and culture of the college, and to integrate them into an intellectual community of faculty and peers.

\section{Statement of Competing Interests}

The authors have no competing interests.

\section{List of Abbreviations}

\author{
SDEV: Student Development Course \\ FYE: First Year Experience \\ GPA: Grade Point Average \\ I-E-O: Inputs-Environment-Outputs
}

\section{References}

[1] Fike, D.S. and Fike, D, "Predictors of first-year student retention in the community college," Community College Review, 36(2). 6888. Apr. 2008.

[2] Tinto, V, Leaving college: Rethinking the causes and cures of student attrition, University of Chicago Press, Chicago, 2005.

[3] Upcraft, M.L., Gardner, J.N., Barefoot, B.O., and Associates, Challenging \& supporting the first-year student. A handbook for improving the first year of college, John Wiley \& Sons, San Francisco, 2005.

[4] Roman, M. A., Taylor, R. T., and Hahs-Vaughn, D, "The retention index of the community college survey of student engagement: How meaningful is it?” Community College Journal of Research \& practice, 34(5). 386-401. Aug. 2010.

[5] Schofield, C., and Dismore, H,"Predictors of retention and achievement of higher education students within a further education context, Journal of Further \& Higher Education, 34(2) 207-221. Apr. 2010.

[6] Reason, R.D., Terenzini, P.T., and Domingo, R.J, "Developing social and personal competence in the first year of college," The Review of Higher Education, 30, 271-299. Jan. 2007.

[7] DeBerard, M.S., Spielmans, G.I., \& Julka, D.L, "Predictors of academic achievement and retention among college freshmen: A longitudinal study,” College Student Journal, 38, 66-80. Jan. 2004.

[8] Pittman, L.D. and Richmond, A, "University belonging and friendship quality during the transition to college: Links to selfperceptions and psychological symptoms," Journal of Experimental Education, 76, 343-361. May 2008.
[9] Schrader, P.G., and Brown, S.W, "Evaluating the first year experience: Students' knowledge, attitudes, and behaviors," Journal of Advanced Academics, 19(2), 310-343. Apr. 2008.

[10] Pascarella, E.T. and Terenzini, P.T, How college affects students: A third decade of research (vol. 2), Jossey-Bass, San Francisco. 2005.

[11] Hunter, M.S. and Linder, P, "Chapter sixteen: First-year seminars.” In M.L. Upcraft, J.N. Gardner, and B.O. Barefoot (Eds.), Challenging and supporting the first-year student: A handbook for improving the first year of college Jossey-Bass, San Francisco, 2005, 275-291.

[12] Gardner, J.N., Barefoot, B.O., and Swing, R.L, Guidelines for evaluating the first-year experience (two-year college and fouryear college editions). University of South Carolina, National Resource Center for the First-Year Experience, Columbia, 2001.

[13] Smith, J.S. and Wertlieb, E.C, "Do first-year college students' expectations align with their first-year experiences?" NASPA Journal, 42(2), 153-174. May 2005.

[14] Swing, R, (Ed.), Proving and improving: Strategies for assessing the first college year (Monograph No. 33), National Resource Center for The First-Year Experience and Students in Transition.University of South Carolina, Columbia, 2001.

[15] Ewell, P, “Observations on assessing the first-year experience," In R.L. Swing (Ed.), Proving and improving: Strategies for assessing the first college year (Monograph No. 33), National Resource Center for the First-Year Experience and Students in Transition, University of South Carolina, Columbia. 2001, 3-5.

[16] Reason, R.D, "Student variables that predict retention: Recent research and new developments," NASPA Journal, 46(3), 482-501. Jul. 2009.

[17] Tinto, V, "Dropout from higher education: A theoretical synthesis of recent research,” Review of Educational Research, 45, 89-125. Jan. 1975.

[18] Astin, A.W. What matters in college? Four critical years revisited, Jossey-Bass, San Francisco, 1993.

[19] Astin, A.W. and Associates. The American freshman: Thirty-year trends, Higher Education Research Institute, UCLA Graduate School of Education, Los Angeles, 1988.

[20] Chickering, A.W. and Reisser, L, Education and identity (2nd ed.), Jossey-Bass, San Francisco, 1993.

[21] Chism, L., Baker, S., Hansen, M., and Williams, G, "Implementation of first-yearseminars, the summer bridge academy, and themed learning communities," Metropolitan Universities Journal 19(2), 8-17. May 2008. [Online]. Available: http://www.cumuonline.org/mujAbstracts.aspx. [Accessed Jan. 5, 2012].

[22] Horn, L. and Nevill, S, Profile of undergraduates in U.S. postsecondary education institutions: 2003-04: With a special analysis of community college students (NCES 2006-184). U.S. Department of Education, Washington, DC, 2006.

[23] O'Gara, L., Karp, M.M., and Hughes, K.L, Student success courses in the community college: An exploratory study of student perspectives, Community College Research Center, Columbia University, Teachers College, New York, 2008.

[24] Pascarella, E.T. and Chapman, D.W, "Validation of a theoretical model of college withdrawal: Interaction effects in a multiinstitutional sample." Research in Higher Education, 19, 25-48. Jun. 1983.

[25] Pascarella, E.T., \& Terenzini, P.T, Measuring outcomes of college: Fifty years of findings and recommendations for the future, Jossey-Bass, San Francisco, 1979.

[26] Bean, J. and Metzner, B, "A conceptual model of nontraditional undergraduate student attrition," Review of Educational Research, 55, 485-540, May 1985.

[27] Swail, W.S., Redd, K. and Perna, L, "Retaining minority students in higher education: A framework for success.” In A. Kezar (Ed.), ASHE-ERIC Higher Education Report, 30(2), Wiley, Hoboken, NJ, 2003.

[28] Palmer, M., O'Kane, P. and Owens, M, "Betwixt spaces: student accounts of turning point experiences in the first-year transition," Studies In Higher Education, 34(1), 37-54, Jan. 2009.

[29] Pike, G.R., Hansen, M.J. and Lin, C.H, "Using instrumental variables to account for selection effects in research on first-year programs," Research in Higher Education, 52(2), 194-214, Apr. 2010.

[30] Hendel, D.D, "Efficacy of participating in a first-year seminar on student satisfaction and retention" Journal of College Student Retention, 8, 413-423, Jul. 2007. 
[31] Reason, R.D., Terenzini, P.T., \& Domingo, R.J, "Developing social and personal competence in the first year of college" The Review of Higher Education, 30, 271-299. Mar. 2007.

[32] Palmer, M., O'Kane, P. and Owens, M, "Betwixt spaces: student accounts of turning point experiences in the first-year transition," Studies In Higher Education, 34(1), 37-54, Jan. 2009.

[33] U.S. Department of Education. Institute of Education Sciences, National Center for Education Statistics. Digest of Education Statistics, 2007 (NCES 2008-022). 2008. [Online]. Available: http://www2.ed.gov/programs/idueshsi/index.html. [Accessed Jan. 5, 2012].

[34] King, J, Gender equity in higher education: 2010 American Council on Education, Washington, D.C., 2010.

[35] Newbold, J., Mehta, S. and Forbus, P, “A comparative study between non-traditional students in terms of their demographics, attitudes, behavior and educational performance,” International Journal of Education Research, 5(1), 1-24, Jan. 2010.

[36] Gandara, P., Alvarado, E., Driscoll, A. and Orfield, G, Building pathways to transfer: Community colleges that break the chain of failure for students of color, 2012. [Online]. Available: http://files.eric.ed.gov/fulltext/ED529493.pdf. [Accessed May. 14, 2012].

[37] Edman, J.L. and Brazil, B, "Perceptions of campus climate, academic efficacy and academic success among community college students: An ethnic comparison," Social Psychology of Education: An International Journal, 12(3), 371-383, Aug. 2009.

[38] Garcia, M, "When Hispanic students attempt to succeed in college, but do not," Community College Journal of Research \& Practice, 34(10), 839-847. Oct. 2010.

[39] Vaughn, G.B, The community college story, University of Chicago Press, Chicago, 2006.

[40] Rhoads, R., Buenavista, T.L. and Maldonado, D.E, Retention Project: Theoretical Contributions and the Role of SelfEmpowerment . American Educational Research Journal, 42(4), 605-638, Oct. 2005.

[41] Tinto, V, Completing college: Rethinking institutional action,University of Chicago Press, Chicago, 2012.

[42] Berger, J.B. and Lyon, S.C. "Past to present: A historical look at retention," In A. Seidman, College student retention, Praeger Publishers, Westport, 2005, 1-29.

[43] Derby, D.C. and Smith, T, “An orientation course and community college retention," Community College Journal of Research and Practice, 28, 763-773. Nov. 2004.

[44] Porchea, S.F., Allen, J.R., and Phelps, R.P, "Predictors of longterm enrollment and degree outcomes for community college students: Integrating academic, psychosocial, socio-demographic, and situational factors," Journal of Higher Education, 81(6), 680708, Oct. 2010.

[45] Adams, C. "Colleges try to unlock secrets to student rentention," Education Digest 77(4), 19, 77, Apr. 2011.

[46] Allen, I.E. and Seaman, J. Online nation: Five years of growth in on line education. The Sloan Consortium. 2007

[47] Crisp, G. and Nora, A, "Hispanic student success: Factors influencing the persistence and transfer decisions of Latino community college students enrolled in developmental education,” Research in Higher Education, 51(2), 175-194. Apr. 2010.

[48] Mattson, C. Beyond admission: Understanding pre-college variables and the success of at-risk students. Journal of College Admission, (196), 8-13, Jan. 2007.

[49] Perez, P.A. and McDonough, P.M, "Understanding Latina and Latino college choice,” Journal of Hispanic Higher Education 7, 249-265, Apr. 2008.

[50] Friar, A.H. and Hawes, D.P, "Competing explanations for minority enrollments in higher education," Journal of Public Administration Research and Theory, 22(1), 83-99. Jan. 2012.

[51] Snyder, T.D. and Dillow, S.A. Digest of education statistics 2009 (NCES 2010-013). National Center for Education Statistics, Institute of Education Sciences, U.S. Department of Education, Washington, D.C., 2010.

[Online]. Available: http://nces.ed.gov/pubs2010/2010013.pdf. [Accessed Mar. 14, 2012].

[52] Hussar, W.J. and Bailey, T.M. Projections of Education Statistics to 2017 (Publication No. NCES 2008078). U.S. Department of Education, National Center for Education Statistics, Washington, D.C., 2008. [Online]. Available:

http://nces.ed.gov/pubsearch/pubsinfo.asp?pubid=2008078. [Accessed Mar. 14, 2012].
[53] Barefoot, B.O. "The first-year experience: Are we making it any better?” About Campus, 5, 12-18, Jan. 2000.

[54] Cuseo, J.B, "Course-evaluation surveys and the first-year seminar: Recommendations for use,” In R. L. Swing (Ed.), Proving and improving: Strategies for assessing the first college year (Monograph No. 33), National Resource Center for The First-Year Experience and Students in Transition, Columbia, 2001, 65-74.

[55] Gardner, J.N, "Starting a freshman seminar program,” In M.L. Upcraft, J.N. Gardner and Associates (Eds.), The freshman year experience, Jossey- Bass: San Francisco, 1989, 238-249.

[56] Tinto, V. and Pusser, B, Moving from theory to action: Building a model of institutional action for student success, National Postsecondary Education Cooperative, Department of Education, Washington, D.C., 2006.

[57] Kuh, G.D., Schuh, J.H., Whitt, E. and Kinzie, J. (2010). Student success in college: creating conditions that matter, Jossey-Bass, San Francisco, 2010.

[58] Rendón, L.I, "Beyond involvement: Creating validating academic and social communities in the community college," Paper presented at the American River Community College, 1994.

[59] Spady, W.G, "Dropouts from higher education: An interdisciplinary review and synthesis,” Interchange, 1, 64-65, Jan. 1970.

[60] Padilla, R.V, “College student retention: Focus on success," Journal of College Student Retention, 1(2), 131-145. Apr. 1999.

[61] Rendón, L.I., Jalomo, R.E. and Nora, A, “Theoretical considerations in the study of minority student retention in higher education," In J. M. Braxton (Ed.), Reworking the student departure puzzle," Vanderbilt University, Nashville, 2000, 127156.

[62] Astin, A.W, "Student Involvement: A developmental theory for higher education,” Journal of College Student Personal, 24, $297-$ 308, Jun. 1984

[63] Amenkhienan, C.A. and Kogan, L, "Engineering students' perceptions of academic activities and support services: Factors that influence their academic performance," College Student Journal 38(4), 523-541, Oct. 2004.

[64] Bailey, T. and Alfonso, M, Paths to persistence: An analysis of research on program, Lumina Foundation for Education, Indianapolis, 2005.

[65] Metz, G.W, "Challenge and changes to Tinto's persistence theory: A historical review," Journal of College Student Retention Research Theory and Practice, 6, 191-207, Jan. 2004.

[66] Elkins, S., Braxton, J. and James, G, “Tinto’s separation stage and its influence on first semester college student persistence," Research in Higher Education, 41(2), 251-268, Apr. 2000.

[67] Deil-Amen, R, "Beyond remedial dichotomies: Are 'underprepared' college students a marginalized majority?” New Directions for Community Colleges, 59-71, Jan. 2011.

[68] Voorhees, R.A, "Toward building models of community college persistence,” Research in Higher Education, 26(2), 115-129, Apr. 1987.

[69] Braxton, J.M., Sullivan, A.V., Johnson, R.M, “Appraising Tinto’s theory of college student departure,” In J.C. Smart (Ed.), Higher education: Handbook of theory and research,(vol. XII), Agathon Press. New York, 1997, 107-164.

[70] Tinto, V, "Classrooms as communities: Exploring the educational character of student persistence," The Journal of Higher Education, 68, 599-623, Nov. 1997.

[71] Hurtado, S. and Carter, D.F, "Effects of college transition and perceptions of the campus racial climate on Latino students' sense of belonging," Sociology of Education, 70(4), 324-345, Oct. 1997.

[72] Durkheim, E, ([1987] 1951). Suicide, Free Press, New York, 1987, 1951.

[73] Barefoot, B.O., \& Gardner, J.N, Achieving and sustaining institutional excellence for the first year of college, Jossey-Bass, San Francisco, 2005.

[74] Howard, H.E. and Jones, W.P, "Effectiveness of a freshmen seminar in an urban University: Measurement of selected indicators,” College Student Journal, 34, 509-515, Nov. 2000.

[75] White, E., Goetz, J., Hunter, M. and Barefoot, B, "Creating successful transitions through academic advising,” In M. Upcraft and G. Kramer, First-year academic advising: Patterns in the present, pathways to the future (Monograph No.18), National Resource Center for the Freshman Year Experience and Students in Transition, University of South Carolina, Columbia, 1995, 2534. 
[76] Cohen, A.M. and Brawer, F.B, (2008). The American community college (5th ed.), Jossey-Bass, San Francisco, 2008.

[77] Jardine, A. and Krause, K, "Once they arrive how do we keep them? Student persistence research and implications for the retention of non-traditional students," Enhancing Student Success Conference, 2005. [Online]. Available: http://www.ccc.newcastle.edu.au/studentsupport/2005conference/ Ann\%20Jardine.pdf. [Accessed Jan. 11, 2013].

[78] Gordon, V.N. (Ed.), Issues in advising the undecided college student (Monograph No. 15), University of South Carolina, National Resource Center for the Freshman Year Experience. Columbia, 1994.

[79] Jones, R. and Becker, K, "Getting Prepared for the Underprepared,” The Mentor, 4(2), Apr. 2002. [Online]. Available: http://www.psu.edu/dus/mentor/020415rj.htm. [Accessed Feb. 8, 2013].

[80] Willging, P.A. and Johnson, S.D, "Factors that influence students' decision to dropout of online courses," Journal of Asynchronous Learning Networks 8(4), 2-15, Jan. 2004. [Online]. Available: http://sloanconsortium.org sites/default /files/v13n3_10willging_0.pdf. [Accessed Feb. 8, 2013].

[81] Workman, J.J. and Stenard, R.A, "Student support services for distance learners,” DEOSNEWS, 6(3), Oct. 1996. [Online]. Available:

http://www.ed.psu.edu/acsde/deos/deosnews/deosnews6_3.asp. [Accessed Feb. 8, 2013].

[82] Leveille, D.E, "An emerging view on accountability in American higher education," Research \& Occasional Paper Series: CSHE.8.05, Center for Studies in Higher Education, University of California, Berkeley, 2005. [Online]. Available: http://cshe.berkeley.edu/. [Accessed Feb. 8, 2013].

[83] Aud, S., Hussar, W., Kena, G., Bianco, K., Frohlich, L., Kemp, J. and Tahan, K, The Condition of Education 2011 (NCES 2011-033), National Center for Education Statistics, Institute of Education Sciences, U.S. Department of Education, Washington, D.C. 2011.

[84] Ayers, D. F, "Mission priorities of community colleges in the southern United States," Community College Review, 30(3), 1-15, Jun. 2002.

[85] Thayer, P.B, "Retention of students from first generation and low income backgrounds, Opportunity Outlook, 2-8, 2000.

[86] Schmidt, P, “Academe's Hispanic Future: The nation's largest minority group faces big obstacles in higher education, and colleges struggle to find the right wasys to help," The Chronicle of Higher Education, Nov. 28, 2003. [Online]. Available:
http://chronicle.com/article/Academe-s-Hispanic-Future/20497. [Accessed Jan. 28, 2013].

[87] Cavanagh, S, "Barriers to college: Lack of preparation vs. financial Need. Education Week, 23(19), 1 and 13, Jan. 2004. [Online]. Available:

http://www.edweek.org/ew/articles/2004/01/21/19access.h23.html. Accessed Apr. 4, 2013.

[88] Ross, T., Kena, G., Rathbun, A., KewalRamani, A., Zhang, J., Kristapovich, P. and Manning, E, Higher education: Gaps in access and persistence study. Statistical analysis report. NCES 2012-046, National Center for Education Statistics, Washington, D.C., 2012.

[89] Newbold, J., Mehta, S. and Forbus, P, “A comparative study between non-traditional students in terms of their demographics, attitudes, behavior and educational performance, International Journal of Education Research, 5(1), 1-24, Jan. 2010.

[90] Porter, S.R. and Swing, R.L, "Understanding how first-year seminars affect persistence," Research in Higher Education, 47(1), 89-109, Jan, 2006.

[91] Allan, E, Women's status in higher education: Equity matters, Jossey-Bass, San Francisco, 2011.

[92] Lau, L.K, "Institutional factors affecting student retention," Education, 124(1),126-137, Jan. 2003.

[93] Levitz, R. and Noel, L,Taking the Initiative: Strategic moves for retention, USA Group Noel-Levitz, Inc., Iowa City, 2000.

[94] Terenzini, P., Rendón, L., Upcraft, M., Millar, S., Allison, K., Gregg, P. and Jalomo, R. "The transition to college: Diverse students, diverse stories,” In F. Stage, J. G. Anaya, D. Bean, Hossler, and G. Kuh (Eds.), ASHE reader series: College students: The evolving nature of research, Simon \& Schuster Custom Publishing, Needham Heights, MA, 1996, 54-65.

[95] Rovai, A.P, "Building classroom community at a distance: A case study," Educational Technology Research and Development Journal, 49(4), 35-50, Jan. 2001.

[96] Bragg, D.D, "Contemporary vocational models and programs: What the research tells us," New Directions for Community Colleges, 25-34, Jan. 2002.

[97] Seybert, J.A, “Assessing student learning outcomes," New Directions for Community Colleges, 55-66. Jan. 2002.

[98] U.S. Department of Education, Institute of Education Sciences, National Center for Education Statistics, Digest of Education Statistics, 2007 (NCES 2008-022), 2008. [Online]. Available: http://www2.ed.gov/programs/idueshsi/index.html. [Accessed May 5, 2013]. 